issn: $1808-799 \mathrm{X}$

\author{
ano 5 - número 5 - 2007
}

artigo

\title{
CURSOS SUPERIORES DE TECNOLOGIA: DEMOCRATIZAÇÃO DO ACESSO AO ENSINO SUPERIOR?[1]
}

\author{
Marisa Brandão \\ marisabrandao@cefet-rj.br
}

\section{1- INTRODUÇÃO}

Este trabalho tem como objetivo a análise dos assim chamados Cursos Superiores de Tecnologia (CST), um tipo específico de ensino superior que vem sendo difundido amplamente no Brasil a partir da segunda metade da década de 1990, tanto no setor público quanto no privado. Observa-se que a proposta deste tipo de ensino superior não é nova, nem é específica do Brasil, encontrando-se suas origens nos países de capitalismo central.

Tendo como pano de fundo a busca da compreensão e da crítica de qual tem sido a educação historicamente reservada à classe trabalhadora, este texto, inicialmente, apresenta as políticas públicas brasileiras voltadas para implantação destes cursos, ainda nas décadas de 1960 e 1970, a partir dos instrumentos legais de então. Em seguida, explicita como os mesmos são retomados na década de 1990, com base em nova legislação, apresentando, de forma ainda inicial, algumas considerações e estabelecendo uma relação entre os dois momentos. 


\section{2- OS CURSOS SUPERIORES DE TECNOLOGIA NO BRASIL DOS ANOS DE 1960 E 1970}

\section{1- contexto: o significado da modernização}

Para compreender os Cursos Superiores de Tecnologia que foram implantados na década de sessenta, é necessário observá-los como parte de decisões políticas que vinham sendo tomadas pelo Estado brasileiro que, por sua vez, inserem-se no contexto econômico e político internacional. Neste sentido, devemos destacar as discussões de então sobre a necessidade do Brasil modernizar-se.

País da periferia capitalista que já vinha passando por um processo de industrialização pelo menos desde o final da década de 1930 e início dos anos de 1940, o Brasil dos anos de 1960 se vê sob pressão para caminhar em um sentido específico de modernização, sentido este relacionado aos interesses imperialistas dos EUA que já haviam se firmado como potência mundial. A modernização era explicitamente compreendida com base em um evolucionismo econômico-social, bastante semelhante às idéias evolucionistas européias do século XIX que foram úteis ao domínio colonial. Cem anos depois, em meados do século XX, idéias oriundas da intelectualidade estadunidense defendem que todas as nações seguem os mesmos estágios de evolução econômica e social, podendo a defasagem entre elas ser resolvida cronologicamente, passível inclusive de acelerações no tempo. Neste sentido, modernizar-se, desenvolver-se, significaria priorizar "a constituição de um setor dirigente 'com propensão para o progresso', isto é, afinado com a modernização vis-à-vis aos EUA" (Leher: 2005, p.210).

No Brasil, de forma semelhante a outros países latino-americanos, o golpe militar de 1964 significou a opção por este caminho de modernização; seus adeptos associaram-se ao capital estrangeiro, buscando neutralizar aqueles que defendiam idéias nacionalistas, de construção de um caminho específico para o país. Assim,

[...] pressionadas pelas mobilizações populares em favor de uma revolução burguesa que ampliasse direitos elementares (reformas de base), as débeis burguesias locais associaram-se mais estreitamente ao imperialismo, aliança que viabilizou o golpe militar no Brasil e em diversos países latino-americanos. (ibid.).

Era preciso então acelerar o desenvolvimento daquele modelo determinado de modernização para fazer o país avançar, recuperando a sua defasagem diante dos que ditavam o próprio modelo e, neste sentido, o investimento deveria se voltar não apenas para a infra-estrutura econômica, mas também para a ciência, a tecnologia e o sistema educacional, dentre outros campos. Mas, ressalta-se, investimento que busca atender àquele modelo específico de desenvolvimento, no caso, subordinado aos interesses estadunidenses. A base econômica e política para este caminho será dada pelo grande capital nacional, pelas estatais e pelas empresas multinacionais; além disto, os EUA se 
encarregarão de possibilitar, através de diversos convênios, o repasse de recursos e suporte técnico. Para que aquele modelo se sustentasse,

[...] era preciso um aparato de ciência e tecnologia que pudesse adequar o modelo às condições ambientais e sociais do país, formar técnicos dispostos a difundir o novo paradigma e estruturar um ambiente de pesquisa [...] que pudesse fornecer o suporte ao modelo. Os mesmos objetivos pragmáticos orientaram [...] o planejamento educacional e outras áreas tidas como estratégicas para a implementação da modernização conservadora. (ibid., p.214, grifo nosso).

Naquele momento, alguns autores chamaram atenção para 0 tipo de desenvolvimento que vinha ocorrendo no Brasil: um capitalismo dependente. Florestan Fernandes apontará para o significado deste desenvolvimento, que traz consigo subordinação não apenas econômica, mas também política e cultural.

\section{2- Origem e caracterização: a engenharia de operação e as "carreiras de curta duração"}

- O início do debate: ciência versus tecnologia

Em 1961, portanto ainda antes do golpe militar, nossa primeira lei estabelecendo Diretrizes e Bases para a Educação Nacional - a Lei Federal 4024, em seu Artigo 104, possibilitará "a organização de cursos ou escolas experimentais, com currículos, métodos e períodos escolares próprios", tendo sido considerada o primeiro passo formal no sentido de criar cursos superiores diferenciados. No entanto, é a Lei 5540, de 28 de novembro de 1968, que implanta uma Reforma Universitária, que irá "coroar" formalmente todo este processo envolvendo discussões e instrumentos legais, tanto a nível nacional quanto em alguns estados do país, no sentido de se difundir e implantar "cursos profissionais de curta duração, destinados a proporcionar habilitações intermediárias de grau superior" (Artigo 23, Parágrafo $1^{\circ}$ ), isto é, cursos superiores de curta duração de uma maneira geral, em diferentes áreas, para "fazer face a peculiaridades do mercado de trabalho regional" (Artigo 18).

Já nos primeiros anos da década de 1960 se fortalece todo um debate acerca da necessidade de se reformular nosso sistema universitário, considerando-se, dentre outros, dois problemas centrais: primeiro, apesar da expansão do ensino superior no período republicano[2], a pressão, por parte dos jovens, quanto ao acesso aos níveis superiores de educação tornava-se cada vez maior; segundo, a constatação de que nosso sistema universitário estava desvinculado da realidade nacional, não sendo capaz de formar os jovens para enfrentar o processo de desenvolvimento urbano e industrial que ocorria.

No entanto, é preciso deixar claro que, se os problemas eram reconhecidos pelos diferentes setores da sociedade, isto não significava que as explicações para estes 
problemas - e as soluções apontadas -, em uma sociedade de classes como a nossa, fossem as mesmas. Por um lado, existiam aqueles que defendiam um acesso amplo das classes trabalhadoras aos níveis mais elevados de educação, reformulando a educação tradicional, mas não abrindo mão de uma base científica, e sim incorporando as novas bases científicas e tecnológicas que vinham sendo desenvolvidas. Para Florestan Fernandes (ibid., p.60), que assumia uma posição socialista, era necessário construir

[...] uma universidade à altura das exigências educacionais da civilização baseada na ciência e na tecnologia científica [...] uma universidade totalmente nova educacionalmente criadora, intelectualmente crítica e socialmente atuante, aberta ao povo e capaz de exprimir politicamente os seus anseios mais profundos.

Por outro lado, no contexto deste debate sobre a necessidade de se reformular a educação e, em especial, a educação superior, são discutidas, ainda na primeira metade da década de 1960, algumas propostas governamentais visando à implantação de cursos superiores diferentes dos tradicionais. Uma das características específicas destes cursos seria o fato de serem organizados com base em uma duração mais curta e, portanto, em uma perspectiva distinta daquela de Florestan. A literatura a respeito indica pareceres do então Conselho Federal de Educação (CFE)[3], de 1962, como tendo dado respaldo para que a Diretoria do Ensino Superior (DES, mais tarde Departamento de Assuntos Universitários - DAU), do Ministério da Educação e Cultura (MEC), encaminhasse a este Conselho proposta de criação de uma modalidade distinta de engenheiros. Estes seriam formados em cursos denominados engenharia de operação,

[...] de curta duração, para atender demandas da indústria, em especial da automobilística que, em função do crescente desenvolvimento tecnológico, passou a exigir um profissional mais especializado em uma faixa menor de atividades, capaz de encaminhar soluções para os problemas práticos do dia a dia da produção, assumindo cargos de chefia e orientando na manutenção e na superintendência de operações. (Brasil, CNE, 2002. Grifo nosso)

Em fevereiro de 1963, o CFE, por meio do Parecer 60/63, aprova esta proposta e, dois anos depois, em fevereiro de 1965, emite o Parecer 25/65 - com base em estudos de uma comissão do DES/MEC - fixando de forma definitiva a nova modalidade de curso de engenheira, lembrando que seria novidade no Brasil, mas já tradicional em países mais industrializados (Nascimento, 1987: p.40). A engenheira de operação será então definida como uma "formação profissional tecnológica, de nível superior", em cursos com duração de 3 anos - em oposição aos "cursos de formação profissional científica, que não se confundem com os primeiros por exigirem preparação científica muito mais ampla e, em conseqüência, maior duração", isto é, de 5 anos (Parecer 25/65, apud Nascimento, 1987: p.40. Grifo nosso.). Este parecer, continuando sua argumentação, deixa ainda mais explícito que o engenheiro de operação, como a própria nomenclatura escolhida mostra, é um profissional com formação voltada para a prática - deve se dedicar à gerência e supervisão das rotinas das indústrias, assim como à utilização e manutenção de 
equipamentos -, portanto, com um nível de conhecimento científico abaixo do "engenheiro graduado" (termo do parecer) que, por sua vez, apoiado em uma formação científica mais sólida, "terá também os encargos de pesquisa e projeto e a característica de sua atuação será a criatividade". Desta forma, percebe-se claramente que o objetivo desta nova política de educação no nível superior - política iniciada antes do golpe militar de 1964, mas reafirmada a partir daí - era formar profissionais que não precisavam pensar, nem crítica nem cientificamente, deveriam apenas reproduzir, operar e manter a tecnologia e os processos industriais que o país importava, principalmente, dos Estados Unidos da América. Além disto, ressalta-se, nossos dirigentes já buscavam referências para este tipo de formação superior nas experiências de outros países.

- O debate também em São Paulo: cursos técnicos de nível superior

No estado de São Paulo, região historicamente mais industrializada do país, também em 1963, em dezembro, seu Conselho Estadual de Educação (CEE-SP), aprova o Parecer 44/63, onde "são levantadas as primeiras justificativas para a criação de uma nova modalidade de profissionais, constituída por 'estudantes que não revelassem bons dotes', para ocuparem funções de 'auxiliares de engenheiros', na indústria” (Peterossi, 1980:p.35). Também neste caso havia referência às experiências de outros países, onde existiam instituições específicas para este tipo de curso - os Colleges of Advanced Technology, na Inglaterra; os Juniors Colleges, nos EUA; os Institutes Universitaires de Technologie, na França e os Tanki Daigaku, no Japão. Ainda em São Paulo, em 1968, o governo do estado solicita ao seu CEE o exame da possibilidade de implantação de uma rede de cursos nos moldes dos Colleges of Advanced Technology. Ao mesmo tempo, constitui um grupo de trabalho para estudar esta possibilidade, fazendo referência a cursos superiores de tecnologia, que venham a atender "à demanda de uma sociedade em continuado desenvolvimento tecnológico", "à contenção de outros graus universitários" e "abra oportunidades ao maior número possível de estudantes".[4] Como resultado deste processo, em 06 de outubro de 1969 é criado o Centro Estadual de Educação Tecnológica de São Paulo (CEET-SP), que mais tarde passará a se chamar Paula Souza (CEET-PS). Em 1970, dentre outras resoluções referentes a este Centro, o Conselho Federal de Educação aprova os planos de curso propostos por esta instituição. Aqui, importa destacar três pontos. Primeiro, a nomenclatura que então se utilizava para este tipo de formação, qual seja, "cursos técnicos de nível superior"; segundo, os cinco cursos que estavam sendo aprovados: "Técnico de Nível Superior em Construções Civis, modalidade 'Edifícios'; idem, modalidade 'Movimento de Terra'; idem, modalidade 'Obras Hidráulicas'; Técnico de Nível Superior em Mecânica, modalidade 'Desenhista-Projetista', e, idem, modalidade 'Oficinas'” (Parecer CFE 278/70). Estes dois primeiros pontos destacados demonstram que não se tratava de cursos de engenharia de operação, a perspectiva era 
mais ampla. No entanto - e este é o terceiro ponto a ser destacado - tratava-se, assim como a engenharia de operação, de cursos com uma duração menor do que os cursos de nível superior então existentes - conforme a proposta de 1970, teriam um total de 2450 horas-aula, em 2 anos de estudos. Em 1973, o CEE-PS havia se transformado em entidade mantenedora, passando a organizar seus cursos em Faculdades de Tecnologia, uma na cidade de São Paulo (FATEC-SP) e outra em Sorocaba (FATEC-SO). Em 1976, segundo dados do CFE e da Secretaria de Ensino Superior do MEC, na cidade de São Paulo, além dos cursos anteriores, havia um novo, Processamento de Dados, enquanto que em Sorocaba o único existente era o de Mecânica: Oficinas. Em 1988, o CEET-PS, em suas duas unidades, oferecia um total de 7 cursos (Bastos, 1991, p.96 e 102). Esta instituição foi uma das poucas que manteve cursos superiores com curta duração ao longo da década de 1990, isto é, antes da reforma educacional por que vem passando o Brasil a partir de 1996. Hoje, segundo informações de seu sítio na internet, "O Centro Paula Souza administra [...] 20 Faculdades de Tecnologia (Fatecs) no Estado de São Paulo. [...] Nas Fatecs, mais de 15 mil alunos estão distribuídos em 20 cursos Superiores de Graduação"[5].

- As iniciativas do governo federal: da engenharia de operação aos "cursos superiores de tecnologia"

Retornando às iniciativas do governo federal, é necessário observar, de um lado, os rumos que foram tomando os cursos de engenharia de operação e, de outro, as iniciativas no sentido de se valorizar os cursos de curta duração de uma maneira mais geral.

Quanto à engenharia de operação, que inicialmente só poderia ser ministrada em instituições de ensino superior de engenharia[6], desde seu início, sofreu grande pressão contrária, tanto por parte dos meios universitários, quanto por parte dos órgãos de representação profissional dos engenheiros. Estes profissionais não aceitavam que, com um curso bem mais curto que os seus, e sem a mesma base científica, alguém pudesse ser considerado engenheiro. A solução encontrada pelo governo militar veio através de um decreto, em 1969[7] - portanto já com base na lei da reforma universitária de 1968 -, onde as Escolas Técnicas Federais foram "autorizadas a organizar e manter cursos de curta duração, destinados a proporcionar formação básica de nível superior e correspondentes às necessidades e características dos mercados de trabalho regional e nacional". Parece ser a partir deste momento que o Departamento de Ensino Médio (DEM) do MEC assume a política dos cursos de engenharia de operação, pois um grupo de estudos foi formado, com apoio da Fundação Ford, incluindo consultores americanos e visitas de brasileiros a instituições de educação técnica nos EUA. Este grupo de estudos resultou na assinatura de um acordo entre o MEC e o Banco Mundial, em 1971, e em um projeto vinculado ao DEM, com o objetivo de instalar 6 Centros de Engenharia de Operação junto a Escolas 
Técnicas Federais. Durante a execução deste projeto, que acabou durando quase nove anos, cerca de 40 brasileiros fizeram mestrado em ciências no exterior (provavelmente nos EUA) com ênfase em educação técnica (Nascimento, 1987: p.44-45). Porém, durante este processo, tanto o curso como os engenheiros de operação continuaram tendo dificuldades de se afirmar no cenário nacional e, em 1976[8], é criada uma nova modalidade de engenharia, a engenharia industrial, também com características de formação de um profissional voltado para a prática - para operar e cuidar da manutenção de equipamentos, para gerenciar processos - porém, com a duração de cinco anos; pois só assim poderia ser considerado como um curso que formasse engenheiros. Em 1977 foi regulamentada a extinção dos cursos de engenharia de operação e, em 1978 - como resultado do acordo entre o MEC e o Banco Mundial -, foram criados 3 Centros Federais de Educação Tecnológica[9] com, dentre outros, o objetivo de "ministrar ensino de grau superior [...] visando à formação de profissionais em engenharia industrial e tecnólogos" (grifo nosso).

É apenas a partir de 1972 que se observa no MEC, em seu Departamento de Assuntos Universitários (DAU), outra iniciativa de incentivo a cursos superiores de curta duração, sendo que então não mais especificamente na área da engenharia, "sugerindo cursos em praticamente todos os setores econômicos" (Nascimento, 1987:p.47). Sendo adotada oficialmente em nível nacional pelas autoridades educacionais, tal política constituiu-se "em projeto específico, integrante do Plano Setorial de Educação 1972/1974, sob n ${ }^{\circ 19}$, 'Incentivo às carreiras de curta duração'”, tendo sua continuidade no MEC/DAU, através do Plano Setorial para 1975/1979, onde "tomaria o n¹5, 'Implantação gradativa das carreiras de curta duração'” (Peterossi, 1980: p.36). A literatura a respeito considera que a partir de então ocorre o verdadeiro impulso para os cursos superiores de curta duração a nível nacional[10]. Para se ter uma idéia de como eram pensados estes cursos, destacamos algumas citações de documentos apresentados por Peterossi (ibid., p.59, 63 e 71, respectivamente; grifo nosso.):

[...] profissionais de carreiras longas são freqüentemente subutilizados, isto é, estão sendo requisitados para funções que poderiam exercer com uma formação muito mais prática e muito mais rápida.[11]

O caráter prático (do curso) permite dispensar as exigências de sedimentação do conhecimento e amadurecimento pessoal de importância no ensino tipicamente universitário.[12]

Procurar-se-á atrair para os cursos de tecnologia aqueles elementos que se 'contentariam com uma formação profissional curta de nível superior'.[13]

Deve-se ressaltar ainda a presença de consultores estadunidenses no desenvolvimento destes dois Projetos do MEC/DAU (Nascimento, 1987: p.47) - projetos que, no entanto, não tiveram continuidade, levando inclusive à desativação da estrutura administrativa que havia sido montada no Ministério a fim de coordenar e supervisionar os cursos de curta 
duração (Bastos, 1991: p.17).

Apesar dos trabalhos disponíveis - poucos - sobre as discussões e iniciativas do governo federal acerca da engenharia de operação e de outros cursos superiores de curta duração[14] comumente tratarem estas políticas públicas de forma distinta, defendemos que, de fato, tratava-se de uma mesma política. Uma política educacional diretamente relacionada ao modelo econômico de capitalismo dependente que visava oferecer uma formação dita de "nível superior" a fim de diminuir as pressões populares por vagas nas universidades, assim como fornecer mão-de-obra adequada ao capital. É verdade que o Estado brasileiro assumia assim seu papel de educador, porém incentivando e oferecendo cursos que qualificariam os trabalhadores dentro dos limites necessários para apenas posto serem cursos de caráter terminal - operar e manter o equipamento e o projeto industrial importado, mas não para criar um projeto de desenvolvimento específico do Brasil. Além disto, estes cursos já poderiam significar a (con)formação de valores sociais condizentes com o modelo econômico-político de subordinação ao império estadunidense como, por exemplo, os novos padrões de consumo necessários a este modelo. A afirmação de que se tratava de uma única política educacional pode ser reforçada ainda por, pelo menos, outros dois aspectos deste processo. Primeiro, a presença constante da "ajuda e cooperação" estadunidense nas duas propostas educacionais - em geral, através de empréstimos que visam trazer consultores dos EUA para o Brasil, assim como levar para aquele país profissionais que têm o potencial de se tornarem os futuros planejadores de nossas políticas[15]. Segundo, as nomenclaturas que foram sendo dadas aos cursos superiores de curta duração[16] sinalizavam para as mesmas características presentes nos cursos de engenharia de operação, isto é, formação de nível intermediário entre o nível médio e o nível superior, assim como formação voltada para a prática. O que aconteceu no Brasil em relação à engenharia de operação foi decorrente a uma forte resistência por parte dos profissionais organizados desta área, fazendo com que fosse necessária uma espécie de correção do rumo nesta área; assim, os esforços do Estado voltaram-se para o que, a partir de 1973, começará a ser difundido como "Cursos Superiores de Tecnologia', dando-se aos diplomados pelos mesmos a denominação de 'Tecnólogos'”[17].

\section{3- OS CURSOS SUPERIORES DE TECNOLOGIA NO BRASIL DE HOJE}

\section{1- Estrutura legal}

Na segunda metade da década de 1990 e primeiros anos do novo século - em uma perspectiva política iniciada antes com o Projeto de Lei 1603, mas facilitada pela 
promulgação da nova LDB em 1996 (Lei 9394, de 20 de dezembro)[18] -, através de uma série de decretos federais e portarias do Ministério da Educação, em conjunto com pareceres e resoluções do Conselho Nacional de Educação (CNE), nosso sistema educacional começa a ser reformulado.[19] Neste contexto, o Decreto 2208, de 17 de abril de 1997, determina, em seu artigo $3^{\circ}$, níveis para a modalidade "educação profissional" básico, técnico e tecnológico[20]. O nível tecnológico é então definido como correspondendo ao nível superior da "educação escolar", com independência em relação a este, e especificamente na área tecnológica. Em seu artigo 10, o referido decreto determina que esses cursos conferem "diploma de tecnólogo". Após algumas polêmicas quanto ao significado de ser um "curso superior", em abril de 2001 o CNE[21] determinou que se trata de um curso de graduação, dando, assim, acesso a qualquer curso de pós-graduação. No mesmo parecer, o Conselho de Educação, estabelece as cargas horárias mínimas para as diferentes áreas - de 1600 a 2400 horas, dependendo da área. Em 2002, um novo parecer, discute as "diretrizes curriculares nacionais para a educação profissional de nível tecnológico", sendo seguido de uma resolução (ambos, instrumentos do CNE[22]) que então "institui as Diretrizes Curriculares Nacionais Gerais para a organização e o funcionamento dos cursos superiores de tecnologia", mantendo aquela carga horária mínima. É, portanto, a partir do Decreto 2208/97 que podemos observar claramente a reiteração de um "sistema de educação profissional" paralelo ao "sistema de educação escolar"; porém, desta vez parece que se consolida a expansão dos limites desta estrutura dual, em termos de níveis, até o superior - são estes os Cursos Superiores de Tecnologia do Brasil de hoje. Cursos que, durante quase duas décadas, haviam ficado no esquecimento.

Em 2004, já no governo Lula, o Decreto 5154, de 23 de julho, revogou o Decreto 2208/97, deixando de estabelecer explicitamente níveis para a Educação Profissional e, portanto, o nível tecnológico; no entanto, em seu artigo 1ํㅜㄹ inciso III, refere-se a "[...] cursos e programas de educação profissional tecnológica de graduação e de pósgraduação" (grifo nosso) que, segundo o artigo $5^{\circ}$, "organizar-se-ão, no que concerne aos objetivos, características e duração, de acordo com as diretrizes curriculares nacionais definidas pelo Conselho Nacional de Educação" (CNE). Não explicita, mas parece assim indicar que toda regulamentação do CNE anteriormente referente aos Cursos Superiores de Tecnologia deverá ser aplicada a esta graduação da Educação Profissional[23]. Sendo assim, continuaremos a denominá-los desta forma para mais facilmente distingui-los dos outros cursos de graduação, o que, em parte, é respaldado pelo próprio Ministério da Educação, posto que em seu sítio na internet não modificou o termo utilizado para se referir a este tipo de curso até a presente data (março de 2006).

Para não criar confusão, é importante esclarecer que, ao mesmo tempo, na esteira 
da reforma, a nova LDB, em seu artigo 44, alínea I, estabelece que a educação superior (aqui como nível da "educação escolar") engloba, dentre cursos e programas, os "cursos seqüenciais por campo de saber, de diferentes níveis de abrangência, abertos a candidatos que atendam aos requisitos estabelecidos pelas instituições de ensino". Posteriormente, o Conselho Nacional de Educação[24] determinou que estes cursos são de dois tipos, sendo um deles "cursos superiores de formação específica, com destinação coletiva, conduzindo a diploma" (Art. $3^{\circ}$, alínea I). Aqui, também após algumas polêmicas quanto ao status de nível superior deste curso, a regulamentação legal acabou determinando que se trata de ensino superior, porém não é uma graduação; sendo assim, seus concluintes podem matricular-se em cursos de pós-graduação lato sensu mas não em stricto sensu. A argumentação legal básica é de que a LDB incluiu estes cursos no nível superior da educação escolar (portanto, são de nível superior), mas colocou-os separadamente dos cursos de graduação (portanto, não são "graduação"). Ao mesmo tempo, os cursos de pós-graduação stricto sensu exigem "diploma em curso de graduação" enquanto os lato sensu apenas exigem "diploma de nível superior", o que reafirmaria a diferença entre "ensino superior" e "curso de graduação". Além destes argumentos, o Parecer 968 procura distinguir os Cursos Seqüenciais de Formação Específica daqueles de graduação a partir das características internas, esclarecendo que os "de graduação requerem formação mais longa, acadêmica ou profissionalmente mais densa do que os seqüenciais". E, de fato, estes acabaram sendo regulamentados com a aceitação de uma carga horária mínima de 1600 horas, que devem ser cumpridas em, no mínimo, 400 dias letivos, (em torno de 2 anos, considerando-se 2 semestres letivos de 4 meses por ano).

\section{2- Qual o ensino superior que se expande?}

Os Cursos Seqüenciais de Formação Específica, de certa forma, nos dão a ponte para percebermos como os Cursos Superiores de Tecnologia, mesmo sendo específicos da educação profissional, estão intimamente associados a uma política educacional mais ampla - iniciada no Brasil ainda nos anos de 1960 - de fragmentação e precarização (sob o manto da "flexibilidade") da educação como um todo, e da educação superior em particular. Aqui, podemos destacar que talvez a estrutura dual de nosso sistema educacional não esteja mais se restringindo ao binômio "educação profissional" $X$ "educação geral". Ao se expandir o acesso das classes populares a níveis mais elevados da educação, oferece-se a estas classes um "tipo especial" de educação, "não tão longa, nem tão densa" quanto aquela, a graduação, a que almejavam - são os Cursos Superiores de Tecnologia ou os Cursos Seqüenciais de Formação Específica. E assim, os defensores desta política, ao comemorarem e afirmarem a democratização da educação colocam, por um lado, que "Igualdade de oportunidades e maior democratização do ensino ... (se 
decidem) indo às escolas e contando quantos pobres havia antes e quantos há agora"; mas por outro lado, eles próprios reconhecem que "profissionalizar" não é o mesmo que "educar" ao falarem de um "[...]belo trabalho de profissionalizar alunos com base acadêmica fraca"[25]. Esta perspectiva nos remete ao início do século passado, quando um importante personagem da educação profissional brasileira escreveu que "não se deve de modo algum incutir no espírito de um proletário a veleidade de querer ser um doutor" (Lüderitz[26] apud Soares, 1982, p.80).

A discussão desta problemática não pode, por sua vez, estar descolada de um contexto ainda mais amplo. É também a partir da crise do capitalismo iniciada em meados dos anos de 1970, com sua reestruturação produtiva (tanto em termos tecnológicos quanto em termos organizativos), que se inserem as atuais políticas educacionais. Se, por um lado, a introdução de novas tecnologias no processo produtivo exige novas qualificações e, ao mesmo tempo, as classes populares vão se organizando e reivindicando acesso a mais elevados níveis escolares; por outro lado, o capital, em sua crise de reprodução, necessita de novos campos; e a educação, sem dúvida, tem se tornado um destes campos. Neste sentido, pode-se perceber que as políticas educacionais brasileiras, nas quais se inserem os novos Cursos Superiores de Tecnologia, têm tido um importante papel no processo crescente de privatização da educação.

Ainda situando o contexto da problemática, cabe ressaltar o tipo de inserção de nosso país nas relações internacionais capitalistas, inserção que leva o Brasil a continuar assumindo o papel muito mais de aplicador da ciência e tecnologia desenvolvidas nos chamados países centrais que de produtor de seu próprio caminho científico e tecnológico.

Ainda se impõem muitas questões que consideramos relevantes nesta discussão, a seguir pontuamos duas. Primeiro, o fato destas políticas estarem presentes, ao mesmo tempo, nos países de capitalismo periférico e central, sugere que isto pode estar representando a divisão entre trabalhadores excluídos e incluídos, nas relações de trabalho estáveis e modernizadas, também no interior dos países centrais. Segundo, os argumentos que dão base às políticas públicas (nacional e internacionalmente) quanto à necessidade de um novo tipo de educação diante das transformações econômicas que vêm ocorrendo nas últimas décadas. Esta questão passa pela diferença entre o discurso e a prática, portanto, pelos diferentes significados que esta educação pode ter, por um lado, para o capital e, por outro, para o trabalho. O discurso que cada vez mais se difunde em relação à educação como um todo declara que esta deve ser estabelecida a partir da construção de uma base sólida, onde a teoria e a prática estejam articuladas, de forma a dar condições para que o estudante desenvolva uma perspectiva crítica e também criativa. No entanto, a prática, no que tange a educação profissional de nível superior em nosso país - lembrando que, ao menos no Brasil, esta formação equivale a (portanto, substitui) qualquer outra graduação - tem sido a de uma educação voltada para postos de trabalho 
específicos[27]. Assim, dá-se continuidade à dualidade presente na história da educação e, como em outros momentos, eleva-se um pouco mais o nível da educação profissional. Tem-se então, de um lado, uma formação sólida, para alguns poucos e, de outro, para a grande maioria (dos que conseguem ir além do Ensino Médio), uma formação de nível superior específica, pontual, voltada estreitamente ao mercado de trabalho. Levantando-se esta questão não se pretende deixar de lado o fato de que maior acesso à educação é importante para as classes trabalhadoras; no entanto, é relevante chamar atenção para qual educação é esta e como atende, distintamente, aos interesses dos trabalhadores e aos interesses da economia capitalista. Se, por um lado, para os trabalhadores, o acesso à educação - resultado de lutas históricas - pode significar maior compreensão da realidade e, portanto, de suas possibilidades de transformação (além da questão imediata de possibilitar aumentos no valor de sua força de trabalho). Por outro, para o capital, esta expansão dos níveis educacionais significa, dentre outros aspectos, o atendimento de suas necessidades quanto à qualificação necessária no processo produtivo modernizado; a necessária (con)formação política e cultural de indivíduos que aceitam o sistema e, portanto, o reproduzem; além de ser mais um campo para a reprodução ampliada do capital.

\section{REFERÊNCIAS BIBLIOGRÁFICAS:}

ARRIGHI, Giovanni. A ilusão do desenvolvimento. Petrópolis, RJ: Vozes, 1997.

BASTOS, João. Cursos superiores de tecnologia: avaliação e perspectivas de um modelo de educação técnico-profissional. Brasília, SENETE, 1991.

BRASIL/Ministério da Educação/Secretaria de Educação Profissional e Tecnológica. Cursos Superiores de Tecnologia Autorizados e Reconhecidos a partir de 2001. SETEC, 2002. Disponível em: <http://portal.mec.gov.br/setec/arquivos/pdf/cst.pdf>. Acesso em: 29 de novembro de 2005.

FERNANDES, Florestan. Universidade brasileira: reforma ou revolução? São Paulo, Alfa Ômega, 1975.

Filho, Domingos Leite Lima. A reforma da educação profissional no Brasil dos anos noventa. Programa de Pós-graduação em Educação, Centro de Ciências da Educação, Universidade Federal de Santa Catarina. Florianópolis, 2002. Tese de doutorado.

KUENZER, Acácia. Ensino Médio e profissional: as políticas do estado neoliberal. São Paulo, Cortez 1997.

LEHER, Roberto. Florestan Fernandes e a universidade no capitalismo dependente. In: FÁVERO, Osmar (org). Democracia e educação em Florestan Fernandes. Campinas, Autores Associados; Niterói, Editora da UFF, 2005, p. 211-245.

MARTINS, Marcos Francisco. Ensino técnico e globalização: cidadania ou submissão? Campinas, Autores Associados, 2000.

NEVES, Lúcia Maria Wanderley. Brasil século XXI: propostas educacionais em disputa. 
RJ, mimeo, 2002.

NASCIMENTO, Oswaldo. O ensino industrial no Brasil: 75 anos do ensino técnico ao ensino superior. RJ, SENAI/DN/DPEA, 1986.

PETEROSSI, Helena Gemignani. Educação e mercado de trabalho: análise crítica dos cursos de tecnologia. SP, Edições Loyola, 1980.

RODRIGUES, José. Ainda a educação politécnica: o novo decreto da educação profissional e a permanência da dualidade estrutural. Revista Trabalho, educação e saúde, v.3, n.2, p.259-282, 2005.

ROMANELLI, Otaíza. História da educação no Brasil (1930/1973). Petrópolis, RJ, Editora Vozes, 1978.

SAVIANI, Dermeval. A nova lei da educação: trajetória, limites e perspectivas. Campinas, Autores Associados, 1999.

SOARES, Manoel de Jesus. As escolas de aprendizes artífices - estrutura e evolução. Fórum Educacional. Rio de Janeiro, 6 (3): 58-92, jul/set 1982.

\section{Marisa Brandão}

Mestre em Educação

Professora de Sociologia do Ensino Médio e Técnico do CEFET-CSF/RJ

Doutoranda da Universidade Federal Fluminense - Faculdade de Educação

[1] Trabalho apresentado na $29^{a}$ reunião anual da Associação Nacional de Pós-Graduação e Pesquisa em Educação (ANPEd), realizada em Caxambu, MG, outubro de 2006.

[2] "De 1800 a 1889 foram criados no Brasil 14 estabelecimentos de ensino superior; de 1890 a 1929, isto é, sob a I República, foram criados mais de 64 estabelecimentos de ensino superior; de 1930 a 1960 foram criados mais de 338 estabelecimentos de ensino superior". CAPES (Coordenadoria de Aperfeiçoamento de Pessoal de Ensino Superior), Estabelecimento de Nível Superior, Série Informação, n 7, Rio de Janeiro, 1960. Citado em Fernandes, 1975: p.46.

[3] O Parecer CFE 58/62 que, ao se referir a uma possível divisão do curso superior "em ciclos sucessivos de estudos, dos quais o primeiro seja básico e, ao mesmo tempo, seletivo para o ciclo profissional imediato [...]", teria firmado "[...] jurisprudência em torno da conveniência da divisão do curso superior universitário" (Peterossi 1980:p.35). Tem-se ainda e o Parecer CFE 280/62 (citado em Brasil, CNE, Parecer 29/2002).

[4] Governo do Estado de São Paulo, Resolução 2001, de 15 de janeiro de 1968, apud Peterossi, 1980:p.35-36.

[5]Centro Estadual de Educação Tecnológica Paula Souza (CEE-PS). Disponível em: 
$<$ http://www.ceeteps.br>. Acesso em: 29 de novembro de 2005.

[6] Decreto 57075, de 15 de outubro de 1965. Na cidade do Rio de Janeiro, estes cursos foram ministrados na Escola Técnica Federal do Rio de Janeiro, a partir de 1966, através de um convênio com a Escola de Engenharia da Universidade do Brasil (Hoje, Universidade Federal do Rio de Janeiro) que, por sua vez, emitia os diplomas por força da lei.

[7] Decreto-lei 547, de 18 de abril de 1969.

[8] Parecer CFE 4434/76.

[9] Respectivamente, Resoluções CFE 5/77 e 5A/77 e Lei 6545 de 30 de junho de 1978.

[10] Na década de 1970, “a expansão desses cursos tem sido considerável, sendo que em relatório do MEC/DAU, de 1976, são mencionados 99 cursos, abrangendo 33 modalidades, oferecidas em 44 instituições de ensino, em 15 estados da federação, [...]” (Peterossi,1980:p.36). A autora refere-se ao Relatório intitulado Estudos sobre a formação de tecnólogos.

[11] MEC/DAU, Projeto 19, 1972, p.23.

[12] VII Seminário de Assuntos Universitários (organizado pelo MEC/DAU). CFE, Revista Documenta, $1974, \mathrm{n}^{\circ} 165$, p.30.

\section{[13] Parecer CFE 1589/75.}

[14] Este texto não trata das chamadas licenciaturas curtas (termo utilizado em oposição à licenciatura plena), no entanto, não poderíamos deixar de incluí-las na mesma perspectiva das políticas de ensino superior aqui discutidas. Não é por acaso que a Lei 5692, de 1971, em seu artigo 30 , estabelece que a formação de professores para o ensino de $1^{\circ}$ Grau exigirá apenas um curso superior de curta duração - a licenciatura de $1^{\circ}$ grau. Esta habilitação acabou sendo extinta com a LDB 9394, de 1996, em seu artigo 62; extinção ratificada pela Resolução CNE/CES 2/99.

[15] Devemos lembrar ainda que esta interferência estadunidense vinha ocorrendo em todos os campos da educação no Brasil, da fundamental à superior, com base nos chamados acordos "MECUSAID” que haviam se iniciado em 1964 (Romanelli, 1991:p.212).

[16] Algumas das nomenclaturas utilizadas, Cursos: profissionais de nível superior, de técnicos de nível superior, de profissionais de nível superior com objetivos específicos, de nível superior de curta duração, superiores de menor duração.

\section{[17] Parecer CFE 1060/73.}

[18] Para uma síntese das disputas políticas em jogo durante o processo de formulação e, posteriormente, de decisão, sobre a LDB, ver Saviani (1999), Martins (2000) e Neves (2002).

[19] Na LDB, nosso sistema educacional passou a ficar dividido em Níveis Escolares - educação básica (Educação infantil, ensino fundamental e ensino médio) e educação superior - e Modalidades - dentre elas, a educação profissional (Título V). Desta forma, além de separar a Educação Profissional daquela denominada escolar, nos artigos 39 a 42 a LDB irá regulamentá-la tão genericamente que permitirá a organização de qualquer estrutura para esta Modalidade.

[20] O nível básico não terá relação com o nível básico da "educação escolar"; o nível técnico terá uma relação de complementaridade com o nível médio da "educação escolar", sendo organizado em estrutura independente do Ensino Médio, porém tendo este como requisito. 
[21] Parecer CNE/CES 436, de 02 de abril de 2001.

[22] Parecer CNE/CP 29/2002, de 03 de dezembro de 2002 e Resolução CNE/CP 03/2002, de 18 de dezembro de 2002.

[23] Não parece ser por acaso que o Parecer 39, de 08 de dezembro de 2004, da Câmara de Educação Básica do Conselho Nacional de Educação (Parecer CNE/CEB 39/2004), ao tratar da possível relação entre Ensino Médio e Técnico (“educação profissional técnica de nível médio", conforme o mesmo Decreto 5154, de 23 de julho), reafirma as Diretrizes Curriculares Nacionais estabelecidas para estes cursos no período de vigência do Decreto 2208/97.

[24] Através da Resolução CNE/CES 01/1999, de 27 de janeiro, baseada no Parecer CNE/CES 968/1998, de 17 de dezembro.

[25] Cláudio de Moura Castro. Os pobres nos cursos técnicos. Revista Veja, Ponto de Vista, 30 de julho de 2003.

[26]João Lüderitz. Relatório. Apresentado a Miguel Calmon Du Pin e Almeida, Ministro da Agricultura, Indústria e Comércio. Rio de Janeiro, Oficinas Gráficas da Lito- Tipografia Fluminense, 1925, p.265.

[27] Os nomes de alguns destes cursos nos dá indicações: Administração de redes de computadores; Automação de serviços executivos; Automação de escritórios e secretariado; Radiologia médica; Web design; Soldagem; Informática com ênfase em Banco de Dados; Gestão em vendas automotivas. 